\title{
Rational design of foundations on soil reinforced by columns
}

\author{
Mounir Bouassida ${ }^{1}$
}

Received: 12 July 2016/ Accepted: 25 August 2016/Published online: 8 September 2016

(C) Springer International Publishing Switzerland 2016

\begin{abstract}
This paper presents a review of the book titled "Design of column-reinforced foundations" that I recently published. The design of foundations on reinforced soil by columns is tackled within a general framework, where several aspects are taken into consideration: modeling of reinforced soil, bearing capacity, settlement, acceleration of consolidation, and improvement of soil characteristics with selected case histories. Unlike existing books on unique improvement techniques (deep soil mixing, stone columns, sand compaction piles) that focus on installation and equipment issues, this one-of-a-kind guide details design purpose. This book rationally handles the design of column-reinforced foundations (CRF) from modeling up to the study of behavior predicted by the numerical analysis and assessed by the field test results. Quasi-exact solutions of the ultimate bearing capacity of soil reinforced by a trench are suggested. The analytical solutions for predicting the settlement of CRF assuming the linear elastic behavior of constituents of soil reinforced by a group of columns are proposed. A novel methodology for the design of CRF is presented and illustrated by different study cases. The improvement of properties of the initial soil due to the installation of stone columns has been evidenced using numerical and experimental investigations. The behavior of foundations resting on soil reinforced by columns has been predicted by numerical 2D and 3D codes. Related results have been assessed after in situ data.
\end{abstract}

Mounir Bouassida

mounir.bouassida@fulbrightmail.org

1 Université de Tunis El Manar, Ecole Nationale d'Ingénieurs de Tunis, LR14ES03 Ingénierie géotechnique, BP 37 Le Belvédère, 1002 Tunis, Tunisia
Keywords Bearing capacity · Design · Modeling · Reinforcement by columns $\cdot$ Settlement $\cdot$ Study of behavior

\section{Introduction}

In recent decades, although several books ([14, 20], etc.) were published on ground improvement along with many conferences held on ground improvement and related topics, there is no book detailing the design and modeling of reinforced soils by columns.

Since 1989, the author has initiated his investigations dealing with soils reinforced by columns at the "Ecole Nationale d'Ingénieurs de Tunis (ENIT)". Such a theme is of interest, because of the quasi-automatic use of deep foundations for versatile infrastructure projects in Tunis, Tunisia. The soil profile in Tunis City is characterized by the presence of a very thick soft clay layer that poses serious challenges for civil engineering foundation designers.

The author's primary action focused on the calculation of bearing capacity of column-reinforced foundations (CRF) using the direct approach of limit analysis (1990-1996). The main finding during this research period consisted in original results obtained by the unit cell, trench, and group-of-columns models [5].

This initial investigation was followed by the settlement prediction and the acceleration of consolidation of CRF. Those issues were tackled in the linear elastic framework using the group-of-columns modeling and a poro-elastic behavior considering the unit cell model (2003-2005). In parallel, the study of the improvement of soft soil characteristics was found of great importance in view of a better understanding of the observed behavior of CRF. Various numerical models led to meaningful findings as published from 2003 to 2014. 
Meanwhile, the homogenization method was found quite interesting for the determination of the bearing capacity of CRF (2001-2006), and the design related to the reinforcement using floating columns (2009).

This set of results (1995-2005), handling both the bearing capacity and the settlement verifications, served to build up a novel methodology for designing CRF. The main benefits of this methodology were the optimization of the treatment cost, and, more importantly, its applicability for all types of soils and columns installation techniques. The methodology was implemented in Columns 1.0 Software that has been commercialized since 2009 by the established consulting bureau in geotechnical engineering, Simpro (http://www.geosimpro.com).

As different design codes are used in several countries, the major merit of the present book for practitioners consists in the design of column-reinforced foundation by a unified method applicable to stone columns, deep mixing method, and sand compaction piles.

The content of the book covers all aspects related to foundations on soil reinforced by columns, including considerations on bearing capacity, settlement, acceleration of consolidation, improvement of soil characteristics due to columns installation, and the study of behavior of such foundation showing the performance of floating columns. First, column-reinforced foundations are introduced, such that even readers who are not familiar with the topic can get acquainted with it easily. Topics on bearing capacity and settlement calculations, design methodologies, acceleration of soil consolidation, and case studies are then systematically introduced. Strength of this book is that it presents the methods of investigations comprising analytical, numerical, and experimental techniques, which are, indeed, necessary in handling complex engineering problems.

This paper summarizes the main results presented in the six chapters included in the book [9] and also points out some new thoughts and open questions in forthcoming research investigations related to the design of foundations on column-reinforced foundations. Some references listed in the book by Bouassida [9] have been included in this paper review.

\section{An introduction to column-reinforced foundations}

Column-reinforced foundations are introduced as a set of in situ ground improvement techniques that consist of installed vertical inclusions to enhance the geotechnical properties of weak and highly compressible soils. Focus is given to the most-practiced worldwide techniques: sand compaction piles (SCP), stone columns, and the deep mixing method (DMM). Advantages and methods of installation provided by the column reinforcement techniques have been illustrated, the types of equipment used, expected performances, and the quality control methods of these techniques are described and reviewed. The mechanical modeling and specific geotechnical properties of the constituents of soils reinforced by columns were presented to carry out all steps of the design and analysis of column-reinforced foundations. Among the very recent methods of installation, special focus was given on the Trenchmix that is a soil improvement process enabling the installation of a network of trenches as a result of cut in situ soil that is then mixed with an added binder. A spread layer is then overlaid for load transfer to the reinforced soil by trenches' network. The Trenchmix process comprises several steps which start with the placement of binder, followed by the mix of ground to be treated by the prepared binder that can be completed by an added fluid [9].

\section{Predicting the ultimate bearing capacity of column-reinforced foundations}

Updated panoramas on the suggested methods that deal with the prediction of the ultimate bearing capacity of a foundation resting on soils reinforced by columns are covered. Classification and criticism of these methods of prediction, and their validation-either by experimental or by numerical investigations-have been deeply discussed.

Focus was given on the prediction of the ultimate bearing capacity of column-reinforced foundations (CRF). First, the earlier methods of prediction are reviewed, classified, and criticized. Second, the developments made, since the nineties in the framework of limit analysis, are summarized in light of the three CRF models which are: isolated column and trench, unit cell, and group of columns. The limit analysis results obtained by the direct approaches and the homogenization method are interpreted and compared to the analytical results predicted by the previous methods $[10,17]$ and recorded test data obtained by Bouassida and Porbaha [6].

The concept of normalized homogenized cohesion was introduced as a relevant parameter for the design of deep mixing method (DMM). Consider both the initial soil, typically soft clay, with cohesion $\mathrm{C}$ and the column material having cohesion $C_{\mathrm{c}}=K_{\mathrm{c}} C$, as purely cohesive media, the homogenized cohesion is defined by the following equation:

$C_{\text {hom }}=\eta C_{c}+(1-\eta) C$

where $\eta$ denotes the improvement area ratio $(\mathrm{IAR})=$ the ratio between the total area of reinforcing columns and the area A of loaded foundation.

The normalized homogenized cohesion is introduced as:

$\langle C\rangle=C_{\mathrm{hom}} / C=1+\eta\left(K_{c}-1\right)$. 


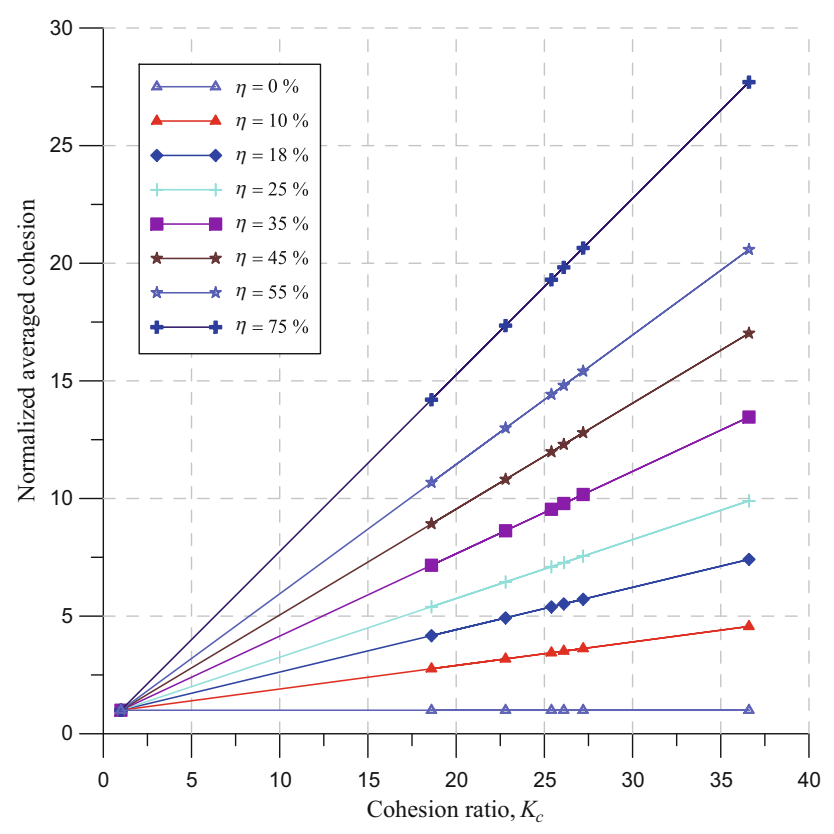

Fig. 1 Variation of the normalized average cohesion vs the cohesion ratio and IAR using recorded data by Bouassida and Porbaha [6]

Figure 1 illustrates the linear variation of normalized homogenized cohesion given by Eq. (2) using a large set of experimental data collected by Bouassida and Porbaha [6] and Bouassida [9].

For the DMM, a bounding of the bearing capacity factor (BCF) was suggested by Bouassida [5]. It is written in terms of the normalized homogenized cohesion as follows:

$2(1+\langle C\rangle) \leq \frac{Q^{*}}{C A} \leq 2(1.828+\langle C\rangle)$.

Inequality (3) provides a general solution of the ultimate bearing capacity of purely cohesive soils reinforced by purely cohesive column material as a function of the normalized homogenized cohesion given by Eq. (2).

Two sets of recorded data were obtained from the loaded-scaled test models up to failure conducted on highly compressible soft clays reinforced by cement columns. These experimental data are used to validate the lower and upper bounds given by Inequality (3). In the range of cohesion ratio: $18 \leq K_{c} \leq 37$ and improvement area ratio $=0.18$, Bouassida and Porbaha [6] compared the analytical predictions with experimental records along with those given by the method of Broms [10]. Figure 2 indicates a thorough assessment of the predictions given by Inequality (3) which fit with the experimental results. In parallel, the prediction by Broms' method seems to be conservative for a normalized homogenized cohesion greater than 10 .

Mazaki et al. [18] ran centrifuge test models on reinforced soil by a group of columns using the deep mixing

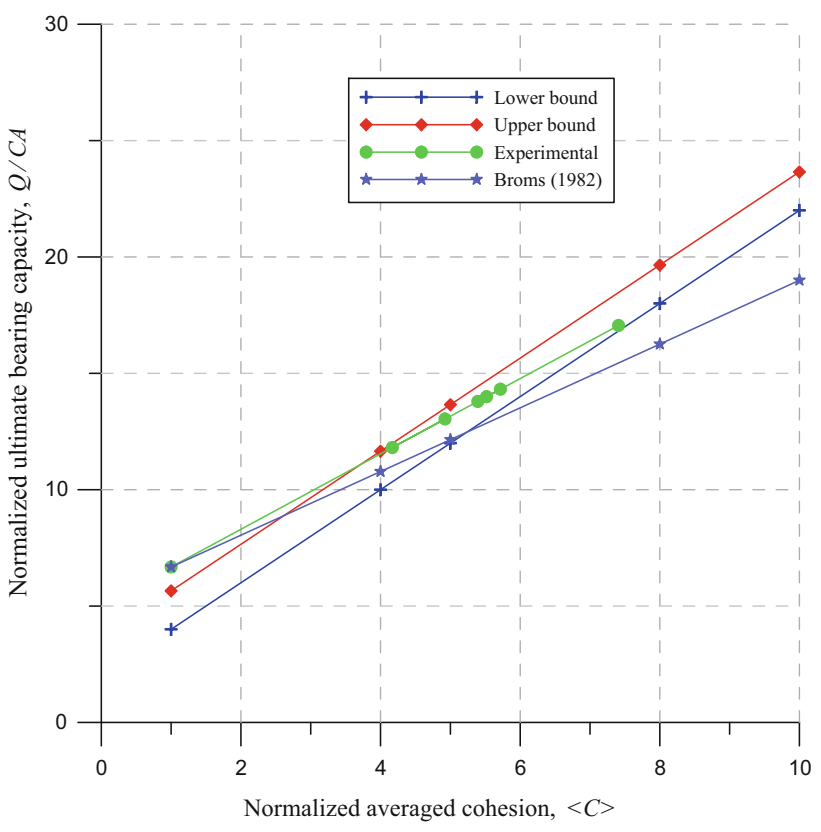

Fig. 2 Experimental validation of the normalized ultimate bearing capacity of purely cohesive reinforced soil in the range of cohesion ratio $18-37$ [9]

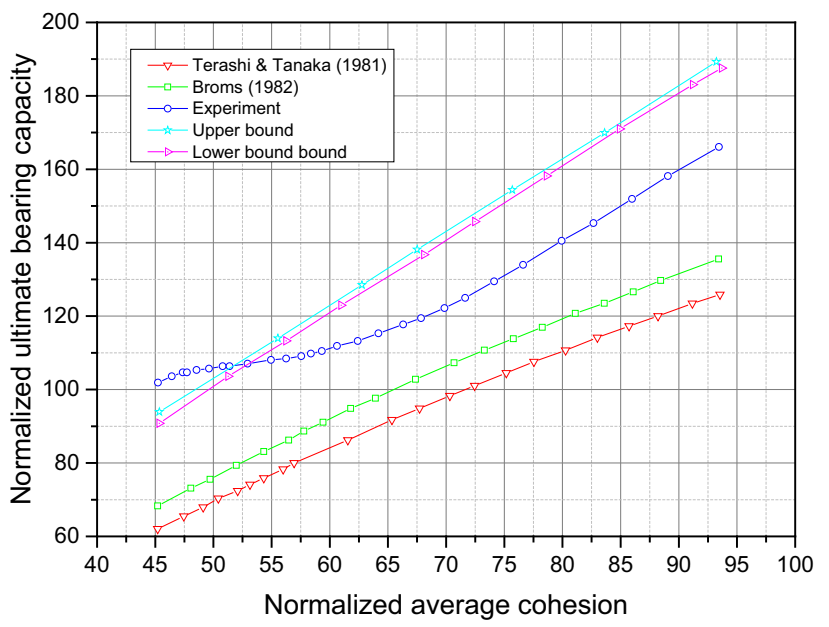

Fig. 3 Experimental validation of the normalized ultimate bearing capacity of purely cohesive reinforced soil in the range of cohesion ratio 62-117 [9]

method in the range of cohesion ratio $62 \leq K_{c} \leq 117$ and $\mathrm{IAR}=79 \%$. Figure 3 confirms that the analytical predictions obtained from Inequality (3) are in good agreement with the recorded data, while those given by the methods of Broms [10] and Terashi and Tanaka [19] significantly underestimate the experimental results.

Kasama et al. [15] performed numerical limit analysis calculation of the ultimate bearing capacity of soil-cement columns. The numerical results provided the same upper bound of the BCF given in Inequality (3). Hence, for the 
case of reinforcement using the deep mixing technique in a wide range of the cohesion ratio and improvement area ratio, analytical predictions by the limit analysis method can be considered as validated. This constitutes a more reliable tool of prediction than the previously suggested methods for the estimation of bearing capacity of foundations on soil reinforced by a group of columns.

\section{Settlement predictions of foundations on reinforced soil by columns}

Methods for the prediction of settlement of foundations on reinforced soil (RS) by columns are introduced and then classified into two categories: empirical and rational methods. The review of rational methods first considers the modeling of RS: the unit cell model (UCM) and the group of columns model. Then, for each type of model, the approach used (e.g., direct or homogenization) and the constitutive laws adopted for constituents of RS by columns are considered. Figure 4 summarizes the classification of methods for the prediction of settlement of a foundation on soil reinforced by columns. Bouassida [9] classified those methods of prediction in two categories, the first category includes those using direct approaches and the second one includes the homogenization approaches.

A method for the prediction of settlement using the group of columns model and the linear elastic behavior framework is detailed [3]. The assessment of the prediction of settlement by several methods is discussed through comparison with recorded data related to two case histories of foundations on soils reinforced by columns. The methods for settlement prediction have been reviewed, where the linear elastic behavior is adopted for both the initial soil and the columns. As a practical result, the settlement reduction, being the principal aim of reinforcement by columns, is expressed in terms of the IAR.

The settlement prediction of a rigid foundation resting upon a RS by end-bearing columns has been investigated by the use of a variational approach in linear elasticity, which provided a lower bound of the apparent Young's modulus of RS from which upper bound settlement estimation is deduced [3]. It follows a secured estimation of settlement of loaded rectangular and circular rigid foundation resting on RS by a group of columns in arbitrary arrangement. The results have been presented in the form of convenient design charts; and these can be used to optimize the IAR for a prescribed load and a given allowable settlement of the foundation. The test results from two cases histories were used to compare several methods of settlement prediction. It has been verified that the settlement prediction by Priebe's method is more secured in comparison to predictions made by several methods adopting the linear elastic behavior for constituents of the RS.

However, the predictions by those linear elastic methods were in good agreement with the measured settlement for different case histories. Finally, it should be noted that a little interest has yet been accorded for the prediction of settlement of foundations resting on compressible clays reinforced by floating columns. Such a case of study deserves a special attention for determining the evolution of settlement of unreinforced compressible layers, since it controls the long-term behavior of the foundation.
Fig. 4 Classification of methods of settlement prediction [9]

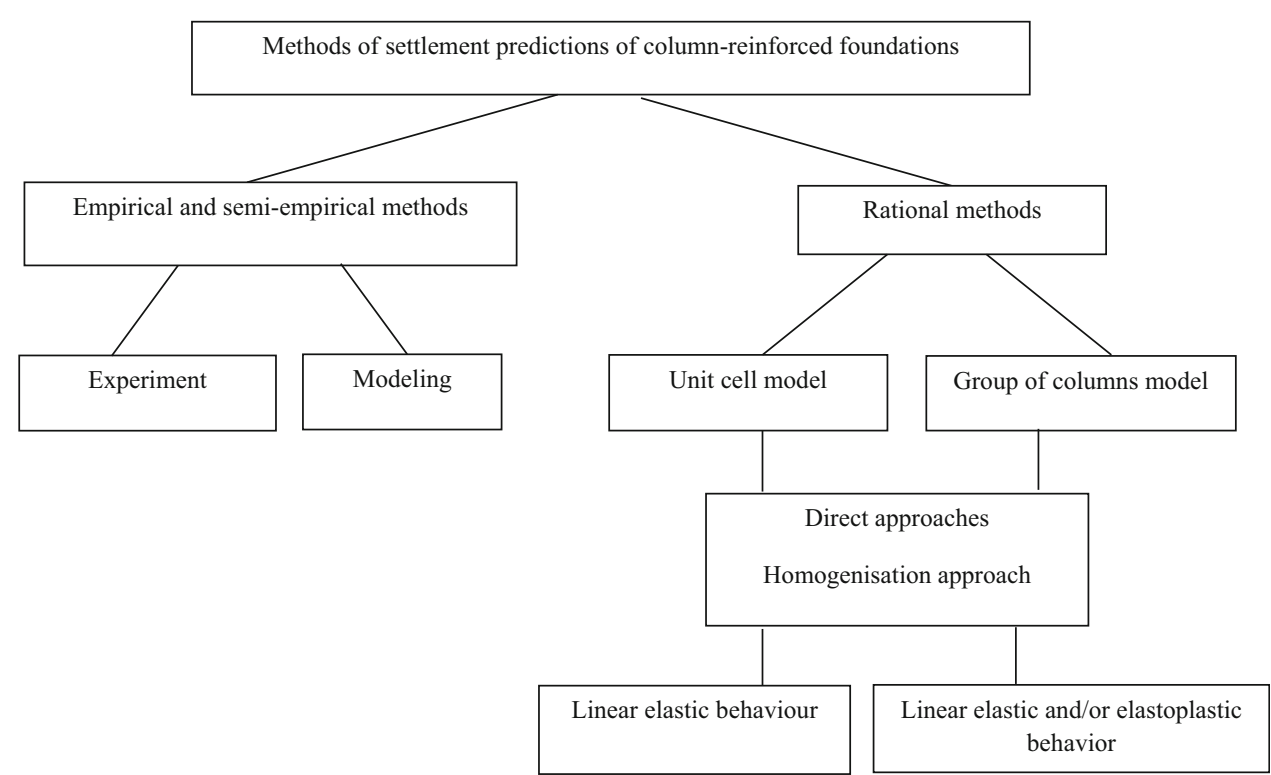




\section{Novel methodology for the design of column-reinforced foundations}

The design of foundations on soft ground reinforced by columns usually involves two important verifications, specifically, checking for adequate bearing capacity and acceptable settlement performance. A comprehensive methodology of design is presented; it successively considers the required bearing capacity and settlement criteria in the design procedure, in contrast to the previous methods of design, which only focus on a unique criterion of design, i.e., settlement or bearing capacity alone. The latter methods are usually dedicated to some specific ground improvement technique. The main advantages of the suggested design method are its validity for all techniques of column installation and its applicability for both endbearing and floating columns.

This comprehensive methodology consists in determining an optimized portion of the foundation area that should be improved by the installation of columns. The optimization is required to avoid an overly conservative design and, consequently, the use of uneconomical quantities of material to construct the column reinforcement.

The basis of the suggested methodology consists of first estimating the minimum improvement area ratio (IAR) required to ensure attainment of the required design bearing capacity of the reinforced soil (RS), and then determining an upper bound or maximum value of IAR by considering the issue of allowable settlement. Optimization is then performed on IAR within the range defied by these bearing capacity and settlement limits. The IAR, which normally controls the cost of soil treatment, was targeted as a quantity to be optimized over a given range, satisfying the performance requirements of the foundation in terms of allowable bearing capacity and settlement.

For practical purposes, the methodology has been implemented in the Columns 1.0 software, which provides a viable tool for optimized and interactive design, being applicable to a variety of geotechnical structures.

Analysis of three case studies provides an illustration of the implementation of this novel design methodology, which has been incorporated in the Columns 1.01 software developed to assist in the design of soil foundations reinforced by columns and to provide cost-effective solutions for this type of foundation. Predicted results demonstrate the efficiency of the proposed methodology in terms of cost effectiveness, specifically avoiding overdesigned solutions. As illustration, the case study of trial embankment at Saga, Japan served for the assessment of design of reinforcement using deep soil mixing floating columns [7]. Using the Columns 1.01 software, and based on recorded settlement in short-term condition, it has been proven that the usually experienced IAR of $30 \%$ for similar projects in Japan was an overestimated solution that can be optimized.

\section{On the behavior of improved soft clay by stone column installation}

The effects of stone columns installation in soft soils are investigated. First, focus is made on the lateral expansion of stone material using the vibro-displacement and substitution techniques by means of numerical simulations and laboratory tests. Second, the behavior of a reinforced soil is studied after the stone column installation to highlight how the properties of soft soils can be improved prior to final loading of the reinforced soil. The effect of such an improvement on the prediction of the settlement of reinforced soil is then evaluated. Two case studies are discussed to highlight the installation effects of stone columns in soft soils.

The numerical study of the improvement of soft soil due to stone column installation induced by lateral expansion has been carried out using the finite-element code 2D Plaxis V9. The numerical dummy material procedure has been performed to simulate the lateral expansion of a single stone column and a group of stone columns in soft clay using two respective reinforced soil models in axisymmetric conditions [11]. Improvement of soft soil properties has been evidenced as a result of the induced primary consolidation in post-installation of stone columns. Numerical predictions carried out by a UCM indicate a better improvement in Young's modulus when the MohrCoulomb constitutive law is adopted for soft clay, rather than the hardening soil model (HSM). Therefore, much better reduction in settlement is predicted when an improved Young's modulus of soft clay is considered [13].

Investigation of an equivalent group of stone columns modeled in axisymmetric conditions led to a conclusion that a significant improvement in Young's modulus is noted with respect to the adoption of the UCM. Importantly, an optimized IAR can be identified when the improvement in Young's modulus of soft soil is considered [12].

An experimental work in laboratory was performed on remolded soft kaolin to estimate its improvement resulting from a laterally expanded stone column within hollow cylindrical remolded kaolin specimens. A granular material is incorporated in the hollow cavity to form the stone column. Such reinforcement was simulated by controlled lateral expansion applied within initially consolidated soft kaolin hollow specimens in the isotropic conditions. Different rates of cavity expansion were tested up to twice the initial volume of the cavity. The lateral expansion was performed in drained conditions, so that the soft Kaolin 
would be completely consolidated under consolidation stress equal to 100,200 , and $300 \mathrm{kPa}$.

After column installation, specimens were subjected to consolidated undrained (CU) triaxial shear tests with recorded excess pore pressure. The effects of consolidation stress and the installation of a stone column were analyzed based on the improvement of undrained Young's modulus and undrained cohesion of kaolin clay.

The main findings that resulted from this experimental program are outlined below:

- The expansion of the cylindrical cavity improves the undrained Young's modulus, $E_{u}$, and the undrained cohesion, $c_{u}$, of the remolded soft Kaolin.

- The increase in undrained shear strength essentially depends on the consolidation stress and the cavity expansion ratio. Such an increase is more pronounced at lower consolidation stress and higher cavity expansion ratio.

- The increase in undrained Young's modulus only depends on the rate of cavity expansion when it is less than 1.5. When the rate of cavity expansion exceeds 1.5 , the improvement in undrained Young's modulus depends, in addition, on the stress of consolidation. If this latter increases, the improvement of Young's modulus decreases.

- As for the undrained Young's modulus, the ratio $\left(E_{\mathrm{u}} / c_{\mathrm{u}}\right)$ increases when the ratio $\left(V / V_{0}\right)$ is less than 1.5 , especially for higher consolidation stresses. It is noted that the ratio $\left(E_{\mathrm{u}} / c_{\mathrm{u}}\right)$ increases when the consolidation stress decreases.

- The dissipation of excess pore pressure after stone column installation turned out to be significant in enhancing the bearing capacity and reducing the settlement of reinforced soil.

A linear poro-elastic model is finally formulated to derive the evolution of primary consolidation settlement by drained column material, for a given history of loading (stage construction). The evolution of consolidation settlement and the degree of horizontal consolidation, under a prescribed load exerted by the foundation, were calculated as functions of the IAR and linear elastic characteristics of the constituents of the UCM. The horizontal coefficient of consolidation of soft soil revealed to be the key parameter that significantly affects the predictions by the suggested poro-elastic model.

\section{Behavior of foundations on soils reinforced by columns}

It is worth to notice, in the existing publications dealing with numerical computations of the behavior of CRF, that the improvement area ratio is often adopted from experienced projects, and, therefore, the optimization of this key parameter was not discussed. Contrarily, in the published book, an optimized improvement area ratio (IAR) is suggested by the methodology proposed by Bouassida and Carter [7] to predict the behavior of foundations on soil reinforced by columns by implementing numerical computations carried out by the Plaxis V9.2D and FLAC3D codes.

Three Tunisian case histories: two oil tanks and an LPG (liquefied petroleum gas) storage facility are investigated. Main conclusions from the numerical investigations are summarized as follows

\section{First case study}

Methods of settlement prediction assuming the linear elastic behavior both for the initial soil and column material were investigated. It is noted that predicted settlement by the FLAC3D code is too close to that obtained by the analytical method proposed by Bouassida et al. [3], which adopts the group of columns model that is similar to the FLAC3D code. The relative difference between those predictions, of 0.59 and $3.74 \%$, for the unreinforced soil and reinforced soil, respectively, is quite negligible. This first case study confirms the usefulness of analytical methods of settlement prediction programmed within the Columns 1.01 software that allows the determination of the optimized IAR.

\section{Second case study}

It is noted that the difference between predicted settlements of unreinforced soil is not significant; therefore, the use of any computational tool (Plaxis or FLAC) or any computation option (either plane strain or axisymmetric study) leads to comparable results from which the reinforcement by columns can be justified. In turn, when dealing with the modeling of reinforced soil, it revealed that the plane strain condition slightly underestimates the settlement prediction. Indeed, such hypothesis is not realistic for cylindrical structures, like oil tanks, for which the axisymmetric condition can be fairly adopted, since its settlement prediction is close to that obtained by 3D modeling [16].

\section{Third case study}

The design of a foundation of bullets of butane and propane (integrated into an embankment) on compressible layers reinforced by floating stone columns was successful [8]. Indeed, this design complied with the allowable settlement of the foundation over 15 years, as predicted by the numerical computations, in the plane strain condition, using the finite-element Plaxis code. These predictions were revealed to be in 
acceptable agreement with the measured settlement of less than $4 \mathrm{~cm}$ over 15 years.

\section{Conclusions and forthcoming development}

Throughout the book by Bouassida [9], the design of foundations on soils reinforced by columns has deeply been investigated in regard to the most viewed benefits, e.g., bearing capacity, settlement, and acceleration of consolidation. Main findings provided by this book can be summarized as follows:

- Introduces a novel methodology of design for all column techniques via an optimized improvement area ratio determined by combining the bearing capacity and settlement verifications that constitute an original result.

- Provides case histories which show that this optimized design is cost-effective compared with the existing methods based either on bearing capacity or settlement considerations.

- Shows the value of the optimized design achieved by elaborated columns through software already in use by geotechnical engineers [4].

- Analysis of the behavior of reinforced soil by columns, carried out by finite-element and finite-difference codes, subjected to various vertically loaded structures, shows the effectiveness of floating columns that can be adopted for reinforcement of thick compressible deposits.

More recently, other investigations have been published on this subject-for example, the performance of stone column-reinforced soft ground under static and cyclic loads [1]. In parallel, at the Research Laboratory of Geotechnical Engineering of the National Engineering School of Tunis, the study of liquefaction mitigation by stone columns also started. Ben Salem et al. [2] reported the primary results regarding the effect of granular column installation on excess pore pressure variation during soil liquefaction. Those very recent published works represent the new trend of forthcoming developments related to the design of column-reinforced foundations.

Acknowledgments The author gratefully thanks Dr Hany Farouk to support the book publication throughout this paper review.

\section{References}

1. Basack S, Indraratna B, Rujikiatkamjorn C (2015) Modeling the performance of stone column-reinforced soft ground under static and cyclic loads. J Geotech Geoenviron Eng. doi:10.1061/ (ASCE)GT.1943-5606.0001378
2. Ben Salem Z, Frikha W, Bouassida M (2015) Effect of granularcolumn installation on excess pore pressure variation during soil liquefaction. Int J Geomech. doi:10.1061/(ASCE)GM.1943-5622. 0000516

3. Bouassida M, Guetif Z, de Buhan P, Dormieux L (2003) Estimation par une approche variationnelle du tassement d'un sol renforcé par colonnes. Rev Fr Géotech 102(1):21-29

4. Bouassida M, Hazzar L (2012) Novel tool for optimized design of reinforced soils by columns. Ground Improv Proc ICE 165(1):31-40

5. Bouassida M (1996) Determination of bearing capacity of rigid foundations resting on reinforced soil by columns (In French). Doctorate ès-Sci Nat Eng Sch Tunis, p 246

6. Bouassida M, Porbaha A (2004) Ultimate bearing capacity of soft clays reinforced by a group of columns-application to a deep mixing technique. Soils Found 44(3):91-101

7. Bouassida M, Carter JP (2014) Optimization of design of column-reinforced foundations. Int J Geomech 14(6):04014031-1-10

8. Bouassida M, Hazzar L (2015) Performance of soft clays reinforced by floating columns. Ground Improvement Cases Histories, Embankments with Special Reference to Consolidation and Other Physical Methods. In: Indraratna et al. (eds) Chap 16. Part Two: sands and gravel piles, stone columns and other rigid inclusions. Butterworth Heinemann Publications. Elsevier, pp 433-449

9. Bouassida M (2016) Design of column-reinforced foundations. J Ross Publ (USA). 224 pages, ISBN: 978-1-60427-072-3

10. Broms BB (1982) Lime columns in theory and practice. Proc Int Conf Soil Mech Mexico, 149-165

11. Debats JM, Guetif Z, Bouassida M (2003) Soft soil improvement due to vibrocompacted columns installation. In: Vermeer et al. (eds) Proc Int Workshop Geotech Soft Soils. Theory and practice. Noordwijkerhout, Netherlands, pp 551-556

12. Ellouze S, Bouassida M, Ben Salem Z, Znaidi MN (2016) Numerical analysis of the installation effects on the behavior of soft clay improved by stone columns. Geomech Geoeng Int J. doi:10.1080/17486025.2016.1164903

13. Guetif Z, Bouassida M, Debats JM (2007) Improved soft clay characteristics due to stone column installation. Comput Geotech 34(2):104-111

14. Indraratna B, Chu J, Rujikiatkamjorn C (2005) Ground improvement case histories: compaction, grouting and geosynthetics, 1st edn. Elsevier, Butterworth-Heinemann. ISBN: 9780081006986

15. Kasama K, Zen K, Whittle AJ (2006) Effects of spatial variability of cementtreated soil on undrained bearing capacity. In: Triantafyllidis T (ed) Proc Num Model of Const Processes in Geotech. Eng. for Urban Env. Ruhr Univ. Bochum, Germany, pp 305-313

16. Klai M, Bouassida M, Tabchouche S (2015) Numerical modeling of Tunis soft clay. Geotech Eng J SEAGS AGSSEA 46(4):ISSN 0046-5828

17. Madhav MR, Vitkar PP (1978) Strip footing on weak clay stabilized with granular trench or pile. Canadian Geotech J 15(4):605-609

18. Mazaki K, Kimihiko O, Shogo M (2000) Centrifuge model tests on failure envelope of column type deep mixing method improved group. Soils Found 40(4):43-55

19. Terashi M, Tanaka H (1981) Ground improved by deep mixing method. Proc 10th Int Conf Soil Mech Found Eng 3:777-780

20. Van-Impe WF, De-Cock F, Van-Der-Cruyssen JP, Maertens J (1997) Soil improvement experiences in Belgium: part II vibrocompaction and stone columns. Ground Improv J 1:157-168 